\title{
Algumas letras, pouca saúde: Campinas, primeira metade do Oitocentos ${ }^{*}$
}

\section{Some letters, little health: Campinas, first half of eighteen hundred's}

\author{
Valter Martins $^{* *}$
}

\begin{abstract}
RESUMO
Em uma região que foi grande produtora de açúcar para exportação e, posteriormente, de café, as preocupações com a educação e a saúde andavam um tanto esquecidas. Os professores eram poucos e as oportunidades de freqüentar escolas eram restritas. Nelas, depois de aprender a obedecer as leis de Deus e do Estado, os alunos aprendiam a ler, escrever e contar. Se o iletramento entre homens livres era grande, entre as mulheres era maior, incluindo muitas esposas de senhores de engenho. Poucos leitores, poucos livros; mas eles existiam: quase sempre religiosos, alguns entretanto sinalizavam interesses de seus donos, como os que tinham como tema a saúde e a doença. Em Campinas, as enfermidades entre livres e escravos eram muitas e eram grandes as dificuldades de receber tratamento de um médico, cirurgião ou boticário. A escassez de homens habilitados "cientificamente" para o exercício da cura motivou tanto ações para suprir a falta daqueles profissionais na região (como a criação de uma Academia Fármaco-Cirúrgica), quanto a ampla atuação de curandeiros entre ricos e pobres, livres e escravos. Muitas famílias, quando suas posses e letras permitiam, se preveniam com pequenas boticas caseiras, nas quais havia de tudo um pouco, ou com livros que poderiam indicar o que fazer em casos de emergência. Lidos em voz alta, esses volumes ajudaram a aliviar dores e a difundir aquilo que muitos denominavam a "verdadeira arte de curar".

Palavras-chave: educação, saúde, Campinas, século XIX.
\end{abstract}

* Dados deste texto estão em Martins (1996) e versão pouco modificada foi apresentada no III Congresso Brasileiro de História da Educação, realizado na PUC-PR. Curitiba, 2004.

** Doutor em História pela Universidade de São Paulo (USP). Professor do Departamento de História da Universidade Estadual de Ponta Grossa - PR (UEPG) 


\begin{abstract}
In a region that had been a big producer of sugar for exportation, and afterwards of coffee, preoccupations with education and health had been a little bit left beside. There was just a little number of teachers and attending schools opportunities were restrict. In these schools, only after learning to obey God's and State Laws, students learned reading, writing and counting. If illiteracy among free men was general, among women it was much bigger, even many wives of sugar-cane farmers. Just a few readers, little number of books: but they existed: they were almost always religious ones, some, however, pointed to their owner's interests, as the ones related to health and sickness. In Campinas, there were a lot of diseases among free people and slaves and there were hard difficulties in relation to medical, surgical or pharmacological treatment. Shortness of men with "scientific" abilities for cure motivated actions in order to supply the lack of such professionals in that region (as the creation of a Pharmacological-Surgical Academy) as well as the wide action of medicine men among rich and poor, slaves or free people. Many families, as their richness and literacy allowed it, prevented themselves with simple home pharmacology, in which there were a little of everything, or with books that could indicate what to do in emergencies. As such books were read aloud they helped to relieve pains and spread what was called the "true cure art".

Key-words: education, health, Campinas, XIX Century.
\end{abstract}

\title{
Introdução
}

$\mathrm{Na}$ antiga capitania ${ }^{1}$ de São Paulo, o bairro rural de Jundiaí, conhecido como Campinas do Mato Grosso, emancipou-se em 1797, tornando-se a Vila de São Carlos, elevada à cidade, em 1842, com o atual nome de Campinas.

Durante as três primeiras décadas do século XIX, a região se desenvolveu graças à lavoura canavieira para exportação, tornando-se a maior produtora de açúcar da província paulista. A cana, aos poucos, foi cedendo terras, capital e mão-de-obra para outro produto que ganhava cada vez mais apreciadores no mundo: o café. Em pouco mais de duas décadas, a partir de meados do Oitocentos, a região de Campinas iria se transformar na principal produto-

1 Província durante o império, estado após a proclamação da república. 
ra e exportadora de café do Brasil, posição que ocupou durante a segunda metade do século XIX e início do XX.

Em 1800, a população local era de 3.620 habitantes, dos quais 1.050 eram escravos. Em 1829, o quadro demográfico havia mudado sensivelmente. Campinas contava então com 8.395 pessoas, sendo que os escravos eram 4.761, ou seja, $56,7 \%$ dos habitantes, indicativo de que a agricultura para exportação, primeiro a açucareira e depois a cafeeira, absorvia cada vez mais braços escravos (MARTINs, 1996, p. 32).

Naquele lugar que ganhava importância econômica e política, as coisas da educação caminhavam lentamente. Afinal, para que estudar muito em um mundo dominado pelo rural, onde o trabalho nos canaviais, cafezais e outras atividades era realizado basicamente pelos escravos? Para a maioria das pessoas a educação não era vista como prioridade e talvez por isso mesmo as oportunidades de estudo fossem tão restritas.

Os professores eram poucos. Entre 1804 e 1809, o padre Diogo Antonio Feijó, futuro regente do império, foi o único professor de latim em Campinas, estabelecendo-se depois na cidade de Itú (QUEIRóz, 1967, p. 237). Nesse mesmo tempo, Custódio Luis Afonso ganhava seu pão com dificuldades, ensinando os mistérios do be-a-bá a meninos. ${ }^{2}$

Em 1817, o jovem reverendo ituano Bernardo José, ${ }^{3}$ era mestre régio de primeiras letras em Campinas. As aulas régias de primeiras letras eram uma criação recente, datando de 1814. (SILVA, 1984, p. 177) Para exercer tal função, o professor deveria saber gramática da língua portuguesa, especialmente ortografia, escrever com "boa forma" e ser "perfeitamente instruído em aritmética" (MENDONÇA, 1961, p. 170).

A principal tarefa desses professores de primeiras letras era, como o nome sugere, ensinar os rudimentos da leitura e da escrita. Quando os alunos principiavam a ler, deveriam passar a fazer cópias de trechos de livros adotados para uso nas escolas de São Paulo:

Os livros, que hão de servir para este fim são os seguintes - um impresso para as primeiras lições das letras e suas combinações na formação de sílabas e palavras: o catecismo pequeno do Bispo de Montpellier,

2 Censos de Campinas, 1806, $1^{\text {a }}$ Companhia, fogo 39. Daqui por diante: C.C., ano, Cia, fogo. A palavra fogo nos censos da época significava domicílio.

3 C.C., $1817,1^{\text {a }}$ Cia, fogo 13. 
recomendado no Alvará de 30 de setembro de 1770, o qual fará depois estudar de cor aos discípulos a fím de se instruírem na doutrina cristã, e principais mistérios de nossa Santa Religião; um compêndio da História de Portugal e das Vidas dos Senhores Reis, nossos Augustos Soberanos; um compêndio das Obrigações Civis do homem nos diferentes Estados, que ocupa no qual [sic] se deduzam os deveres que resultam da sua existência civil já para com Deus, e para com o Soberano, já para consigo e para com os outros homens de per si cujo compêndio deve terminar com as Regras da Civilidade... (MENDONÇA, 1961, p. 171-172).

Depois de aprenderem a obedecer à Igreja e ao Estado, e a ler, era a hora de aprender a escrever, e até se "comportar em sociedade". Os professores enfatizavam o ensino da gramática, ortografia e sintaxe da língua portuguesa, utilizando a Gramática de Lobato e Regras d'Ortografia de Pinheiro. Simultaneamente, os estudos de aritmética seguiam suas lições a partir dos Elementos de Besouth. Nesse ensino básico, o mestre deveria gastar o tempo necessário até que o aluno ficasse apto a ler e escrever perfeitamente, segundo as regras da ortografia, e as quatro operações da aritmética, incluindo problemas simples de contas mercantis. Tudo isso seria incompleto se o aluno não tivesse conhecimentos da doutrina cristã. ${ }^{4}$

A jornada de estudo diário não era das mais leves e o calendário escolar era balizado pelo calendário eclesiástico:

Como todos os exercícios das primeiras letras se fazem na aula, deve o tempo dela durar três horas de manhã e três de tarde, em todo o ano, não tendo os discípulos senão um mês de férias grandes em janeiro, e quinze dias pela Páscoa da Ressurreição e outros tantos pela do Espírito Santo, não tendo em todo o decurso do ano outros feriados se não os três dias imediatos depois da dominga da quinquagésima ${ }^{5}$ e as quintas feiras de cada semana, se nela não houver algum dia que a Igreja manda santificar (MENDONÇA, 1961, p.173).

4 Sobre o tempo escolar, veja: FARIA FILHO, L. M.; VAGO, T. M. Entre relógios e tradições: elementos para uma história do processo de escolarização em Minas Gerais. In: VIDAL, D. G. ; HILSDORF, M. L. S. (Orgs.) Brasil 500 anos: tópicos em história da educação. São Paulo: Edusp, 2001, p. 117-136.

5 Domingo que precede o primeiro domingo da quaresma. 
Esse sistema excluía grande parte dos alunos em potencial porque em um lugar cuja economia era essencialmente agrícola, os meninos e adolescentes das famílias pobres que não possuíam escravos ajudavam no cuidado das plantações e, devido ao trabalho, estavam sujeitos a um calendário diferente do escolar, regido pelo ritmo do plantio e da colheita. Para os que conseguiam estudar, depois de aprender as primeiras letras estavam aptos a seguir seus estudos matriculando-se em gramática latina, grega e retórica, cujas aulas tinham um período de duração de duas horas de manhã e duas à tarde. Dos poucos que freqüentavam as aulas de primeiras letras, uma parcela menor continuava a estudar.

O salário dos professores das aulas régias era pago com recursos obtidos com o "subsídio literário", imposto que incidia sobre a carne verde e aguardente: o dinheiro em geral era pouco e passava por vários descaminhos. ${ }^{6}$ A vida de um professor de primeiras letras não era fácil - além dos parcos salários que não raro atrasavam meses, na velhice, quando não podiam mais trabalhar, eram simplesmente demitidos e poucos eram os que tinham algum pecúlio (SILVA, 1981, p. 126). Um professor de primeiras letras em Campinas, no ano de 1825, tinha uma renda média anual inferior a de carpinteiros (65\$000), barbeiros $(62 \$ 000)$, ourives $(67 \$ 000)$, músicos $(100 \$ 000)$ e caldeireiros (200\$000) (MARTINS, 1996, p. 99-100). ${ }^{7}$

Naquele mesmo ano, Joaquim José de Farias, que vivia de ensinar meninos, tinha uma renda anual de $55 \$ 000 .{ }^{8}$ Ser professor significava levar uma vida de poucos confortos e muitas privações. Essa realidade fazia com que, surgindo uma oportunidade de trabalho melhor remunerado, muitos mestres deixavam de ser mestres ou, pelo menos, mestres em tempo integral (sILVA, 1981).

Dentre os privilegiados iniciados nos mistérios da arte de ler, escrever e contar, as mulheres pouco se faziam representar. A primeira escola pública feminina de Campinas, cuja primeira turma teve 28 alunas, surgiu apenas em 1844. Para as que podiam pagar não faltavam vagas e as meninas aprendiam, efetivamente, pouco mais que coser e bordar (RIBEIRO,1996; RIBEIRO,1997). Escolas e professores particulares davam conta da demanda, aliás, deprimida

6 Cf.: SOUZA, 1986, p.130. ESCHWEGE apud SAINT HILAIRE, 1976, p.79. Documentos interessantes ..., v. 44, p.153.

7 A moeda brasileira no século XIX era o réis: \$300: trezentos réis; 300\$000: trezentos mil-réis; 300:000\$000: trezentos contos de réis.

8 C. C., 1825, $1^{\text {a }}$ Cia, fogo 110. 
(MARIANO, 1979, p. 20). O analfabetismo grassava endêmico mesmo em fazendas cujos proprietários eram bem mais que remediados, notadamente entre as mulheres. Maria Joaquina de Camargo, Ana Francisca de Campos, Maria Joaquina da Silva e Gertrudes Maria Machado eram viúvas de senhores de engenho, todas analfabetas. ${ }^{9}$

\section{Saber e saúde em Campinas}

Desde as primeiras décadas da colônia, os livros e os saberes escolares eram tidos como fontes de problemas para o Estado e para a Igreja. Instrumentos perigosos, os livros e a educação poderiam provocar sedições e perguntas incômodas para a fé. Assim, as escolas não tiveram maiores incentivos por parte da coroa portuguesa, que para completar sua obra de domínio cultural, proibiu a criação de universidades no Brasil (VILLALTA, 2001, p. 347). Além disso, durante anos, prestígio social, e também riqueza, eram medidos quase que exclusivamente pela posse de escravos. Desta forma, se as escolas eram poucas, que dizer dos livros e seus leitores?

Como havia poucos letrados, a posse de livros era mínima. A escassez no consumo de livros refletia a escassez de leitores. Ao relatar o extravio de dois "caixões de livros" em 1802, o Capitão-general da capitania de São Paulo, Antonio Manoel de Mello Castro e Mendonça, ponderava que quase todos os volumes recebidos anteriormente do Rio de Janeiro ainda estavam por ser vendidos, ou seja, estavam literalmente encalhados. Para não ficar com tantos livros, Castro e Mendonça passou a doá-los, pois previa que os mesmos continuariam sem compradores, sugerindo que distribuídos os volumes poderiam cumprir sua função de instrução (Documentos Interessantes... v. 30, p.146149).

Entre os 34 títulos disponíveis, havia 14 voltados a temas agrícolas, como por exemplo: Açúcares do Rio, Considerações cândidas sobre o açú-

9 Respectivamente: Inventário, Centro de Memória da Unicamp, Tribunal de Justiça de Campinas, $1^{\circ}$ Ofício, caixa 54, processo 1389, ano de 1831; Inventário, Centro de Memória da Unicamp, Tribunal de Justiça de Campinas, $1^{\circ}$ Ofício, caixa 120, processo 2730, ano de 1848; Inventário, Centro de Memória da Unicamp, Tribunal de Justiça de Campinas, $1^{\circ}$ Ofício, caixa 49 , processo 1267, ano de 1829. Daqui por diante: Inv, CMU, TJC, Of, cx., proc., ano. 
car, Cultura da canela de Goa, Cultura do cravo, Cultura do linho cânhamo, Fazendeiro do Brasil (que tratava do cultivo da cana), Memórias dos algodoeiros por Arruda, entre outros. Se parecia não haver grande interesse nessas obras em uma capitania eminentemente agrícola, o que seria de títulos como: Canto heróico ou a Ciência das sombras? Em resumo, se o acesso à educação era um privilégio para poucos na primeira metade do século XIX, mais raros ainda eram aqueles que tinham, ou adquiriam, livros.

Em Campinas, um desses raros casos foi o de José Barbosa da Cunha, falecido em $1807,{ }^{10}$ e que possuía em sua casa, entre outros livros: Tesouro de pensamentos, Teologia, Teologia prática, volumes, certamente, imprescindíveis para um cristão letrado daqueles tempos. Ordenações do reino e Comentários de ordenação, preciosos para um súdito português. Entretanto, duas obras indicavam, explicitamente, interesses de seu proprietário: Considerações médicas, em 3 tomos e Farmacopéia. Em época de grande analfabetismo e de poucos homens oficialmente habilitados nas "principais" artes de curar (médicos, cirurgiões e boticários) ${ }^{11}$ os livros, mesmo entre as pessoas que exerciam aquelas artes, eram objetos raros (seria ele um "profissional" da cura?). Assim, entre homens e mulheres, possuir livros, até para emprestá-los a quem mais saber tivesse, e ler sobre idéias médicas, enfermidades, plantas com poderes terapêuticos e mezinhas, poderia fazer grande diferença em momento de doença ou emergência.

Ao mesmo tempo, ler em voz alta sobre questões de enfermidades e cura significava instruir, mesmo que oralmente e de forma precária, as pessoas e assim remediar, o que muitos consideravam abusos quando o tema era saúde/doença. Uma forma de divulgar princípios gerais da "verdadeira arte de curar", isto é, daquela praticada por médicos, cirurgiões e boticários, que pudessem auxiliar os enfermos onde não existiam estes profissionais - uma difusão, que com todas as suas limitações, poderia contribuir para desacreditar os saberes de outros curadores, habilitados ou não. (MARQUES, 2003)

Em 1812, faleceu a viúva de Barbosa da Cunha, Clara Rita de Sousa, ${ }^{12}$ deixando também alguns livros. Entre eles podemos vislumbrar alguns dos

${ }^{10}$ Inv, CMU, TJC, $1^{\circ}$ Of, cx. 4, proc. 99, 1807.

${ }^{11}$ Curador habilitado era aquele autorizado pelo governo a praticar seus conhecimentos, eram eles: além dos médicos, cirurgiões e boticários; os sangradores (ou barbeiros-sangradores), as parteiras e até curandeiros ("especialistas" em tratar doenças da terra com medicamentos locais) (PIMENTA, 2003b). Outros curadores existiram desde os primeiros tempos do Brasil colônia: pajés, benzedeiras, bruxos, feiticeiras, etc. A mistura das "artes" foi uma constante. Cf: SOUZA, 1995, p.151-156.

${ }^{12}$ Inv, CMU, TJC, $1^{\circ}$ Of, cx. 9, proc. 272, 1812. 
volumes que ela havia herdado de seu marido. Além deles, Considerações cândidas imparciais sobre a natureza do açúcar (uma das obras distribuídas por Castro e Mendonça?), Breve resumo para a instrução e direção dos ordenandos e Nobiliarquia portuguesa. Em espanhol, três obras: um livro de geografia, Davi perseguido (2 volumes) e El gran hijo de David. Comentário e construção literal de todas as obras de Horácio e um livro de Virgílio, revelavam gosto pelos clássicos. A religiosidade aparecia em Semana Santa (um volume sem capa). Considerações médicas, título que constava dos volumes de Barbosa da Cunha e Cirurgia reformada (também sem capa e muito velho), continuavam a indicar interesse pelo sadio e o enfermo (ou respeito pela memória do marido) em um tempo em que tanto livres como escravos padeciam, muitas vezes, dos mesmos problemas de saúde.

Entre os cativos, condições inadequadas de alimentação e alojamento, jornada de trabalho longa e cansativa, maus tratos dos feitores: um cotidiano que debilitava a saúde dos escravos, deixando-os expostos a muitas doenças.

Francisco, africano com 30 anos e Adão com 14 anos, escravos de Silvério de Aguiar da Silva, e Florêncio, escravo de Joaquim Ferreira de Camargo, sofriam "achaques de gota". No Sítio Taquaral, de Joaquim Guedes Barreto, havia vários escravos doentes. João Monjolo e Paulo tinham as "mãos desmanchadas". Manoel tinha "desmancho nos pés" e era "alcoolista". ${ }^{13}$ Estariam esses escravos com lepra? É possível que sim. A escrava Luisa era considerada "doentia", termo comum para caracterizar escravos nos inventários. Comum também eram aqueles considerados bêbados ou "alcoolistas".

Os herdeiros do Alferes Francisco Carlos da Silva, morto em 1859, ${ }^{14}$ perderam o escravo Manoel, de 17 anos, avaliado em 2:000\$000 que, segundo relataram, morreu depois de contrair moléstia identificada como tifo, mesmo tendo sido tratado com "todos os recursos da arte" médica. Outro escravo, de 22 anos, de nome Antonio, avaliado em 1:700\$000, padecia de constantes ataques que julgaram ser vertigem. Quando o doutor Ricardo Gumbleton Daunt, um dos médicos mais respeitados de Campinas, examinou esse escravo, concluiu que o mesmo estava com o "vírus sifilítico", que provocava sintomas como dores nos ossos longos e um inchaço considerável na articulação do ombro esquerdo, o que dificultava os movimentos do braço. Para o doutor,

${ }^{13}$ Inv, CMU, TJC, $1^{\circ}$ Of, cx. 42 , proc. 1110,1828 . Inv, CMU, TJC, $1^{\circ}$ Of, cx. 88 , proc. 2059,1839. Inv, CMU, TJC, $1^{\circ}$ Of, cx. 120 , proc. 2730,1848 . Inv, CMU, TJC, $1^{\circ}$ Of, cx. 120 , proc. $2730,1848$.

${ }^{14}$ Inv, CMU, TJC, $1^{\circ}$ Of, cx. 155 , proc. 3282, 1859. 
Antonio estava com o físico "algum tanto aniquilado". Após a consulta, Daunt deu sua opinião a respeito do escravo doente: "Reconhecendo que seu curativo será longo e difícil, e dependente de uma protelada dieta, sou de parecer que seu valor real é de um conto de réis e não mais. 23 de maio de 1861." 15 A avaliação do escravo, realizada durante o inventário dos bens do Alferes Silva, foi revista com base na saúde de Antonio, desta vez, com atestado médico!

Os dois casos servem como exemplo do que afirmou o viajante suíço J. J. von Tschudi sobre o aumento no cuidado com os cativos após $1850,{ }^{16}$ quando seu preço subiu muito e sua morte passou a significar grande prejuízo. O escravo Manoel morreu mas não sem ser tratado com "todos os recursos da arte". Antonio foi assistido por um médico e recebeu dieta especial visando sua recuperação. Provavelmente, se Manoel e Antonio tivessem vivido algumas décadas antes, não teriam conhecido nenhum médico.

Saúde precária e falta de assistência médica não eram exclusividade dos escravos. Em terras onde livros e estudo pouco significavam, eram raros os homens reconhecidos como parte do grupo de maior prestígio nas artes de curar: médicos, cirurgiões e boticários. ${ }^{17}$ Livres e libertos tinham, também, uma saúde que deixava a desejar e todos recorriam a curandeiros e outros curadores. Entretanto, não importava quem fosse procurado para tratar uma enfermidade ou aliviar uma dor, a precariedade da saúde criava problemas para as pessoas que dependiam de seu próprio trabalho para viver (MARTINS, 2004).

João de Siqueira era agricultor, pardo, casado com Gertrudes Franca e tinha três filhos pequenos. Em 1817, ele "nada colheu por andar doente", fato que deve ter colocado ele e sua família em dificuldades. Já Floriano Ferreira, solteiro, 28 anos, "vivia doente a favor de sua irmã Dona Rita". Em 1829, Vicente Bueno de Camargo estava com 31 anos, era casado, tinha três filhos e vivia de "esmola por ser homem doente". ${ }^{18}$

Doença de ricos e pobres, a lepra, muitas vezes percebida como uma maldição divina, fazia várias vítimas em Campinas. Como em outras partes do mundo, o então chamado Mal de São Lázaro ou morféia, era uma das mais

${ }^{15}$ Id. Anexo 1861

${ }^{16}$ A lei Euzébio de Queirós, de 1850, proibiu o tráfico de escravos para o Brasil.

${ }^{17}$ Nesse texto, não pretendo abordar as diferenças (e disputas) entre as atividades de curar reconhecidas na época e as transformações que aconteceram, ainda na primeira metade do século XIX, no campo de atuação desses profissionais. Ver o tema em: PIMENTA, 2003b.

${ }^{18}$ C.C., 1817, $6^{\mathrm{a}}$ Cia, fogo 41. C.C., 1817, $6^{\mathrm{a}}$ Cia, fogo 43. C.C., 1829, $3^{\mathrm{a}}$ Cia, fogo 106. 
temidas enfermidades que afligiam os campineiros, por ser considerada um mal "contagioso, pestilento, incurável" (MACHADO et al.,1978, p. 73). ${ }^{19}$

Francisco Rodrigues Moreira de 60 anos, branco, casado com Ana Francisca, 38 anos, era pai de nove filhos e vivia de esmolas porque padecia de "morféia". Na casa de Escolástica Bueno, tanto ela como seu filho eram "lazarentos" e sobreviviam graças à caridade alheia. O fabricante de louça de barro e agricultor, Felisberto José de Camargo, contraiu o "mal de Lázaro", do qual veio a falecer. ${ }^{20}$

A lepra não escolhia suas vítimas. Os quinze escravos de Joaquim Ferreira de Camargo, ${ }^{21}$ senhor de engenho e proprietário do Sítio das Anhumas, certamente não tinha nenhuma razão para invejar seu amo, que morreu em conseqüência da lepra.

No entanto, entre brancos e libertos, as maiores vítimas das moléstias eram as crianças. Mesmo não fornecendo a idade de forma sistemática e nada dizendo sobre a causa mortis, pode-se notar pelos censos que muitas crianças morriam em Campinas. Caracterizada por seu lado rural, foi entre as famílias de pequenos agricultores que surgiram a maioria dos "anjinhos", pelo menos no primeiro quartel do Oitocentos. ${ }^{22}$ Morando isoladas, não raras vezes vivendo em condições de pobreza e penúria, pouco podia ser feito pelos doentes da família, principalmente crianças, além de rezas, chás e simpatias. Práticas populares que os livros ora condenavam, ora procuravam regular e, assim, controlar.

Mesmo quem tinha melhores condições de vida como um senhor de engenho, também não estava imune às tristezas da perda de um filho muito jovem. José Antonio do Amaral, 32 anos, Alferes de Ordenança e senhor de engenho com 15 escravos no Bairro da Boa Vista, não teve como impedir a morte de seu filho Antonio, que morreu vinte dias após ter nascido. Outro senhor de engenho, Antonio da Silva Leme, chorou a morte de seu caçula e oitavo filho Jesuino, que morreu aos dois anos. ${ }^{23}$

Em 1829, havia mais profissionais da cura em Campinas do que os registrados nos censos de anos anteriores. O alemão Cristiano Frederico Hasse

${ }^{19}$ Sobre a doença como castigo divino: DELUMEAU, 1989, p.140-141. DUBY, 1998, p.87-89. Sobre a lepra veja: BÉNIAC, [19-] $1405,1831$.

${ }^{20}$ C.C., $1803,1^{\circ} \mathrm{Cia}$, fogo 24 . C.C., $1829,7^{\circ} \mathrm{Cia}$, fogo 121 . Inv. CMU, TJC, $1^{\circ}$ Of, cx.55,

${ }^{21}$ Inv, CMU, TJC, $1^{\circ}$ Of, cx. 88, 2059, 1839.

${ }^{22}$ C.C., $1803,2^{\mathrm{a}}$ Cia, fogo 89. C.C., $1800,1^{\mathrm{a}} \mathrm{Cia}$, fogo 95. C.C., 1812, $5^{\mathrm{a}} \mathrm{Cia}$, fogo 47.

${ }^{23}$ C.C., $1800,1^{a}$ Cia, fogo 91. C.C., $1800,1^{a}$ Cia, fogo, 72. 
era cirurgião, como seu colega Francisco Gomes Pereira. Na casa do cirurgião-mor Francisco Alvares Machado de Vasconcelos viviam os boticários Davi de Sousa Dutra, de 20 anos de idade e Joaquim Correia de Melo, de 16 anos. Sendo assim tão jovens, poderiam atuar em conjunto com profissional de maior prestígio para angariar clientela. Entretanto, poderiam também aprender outro ofício, o de cirurgião - para mudar de profissão ou para praticar cirurgia e preparar remédios (o exercício de dois ofícios não era raro, mesmo sendo em geral proibido pela antiga Fisicatura-mor) ${ }^{24}$ Era difícil outro tipo de formação. ${ }^{25}$ Para brancos, mestiços ou negros, a habilidade e o saber apreendidos no contato pessoal eram, ainda, mais valiosos do que os raros livros e "cursos especializados".

Mas, a escassez de profissionais da saúde preocupava. Em sua "Memória Econômico Política da Capitania de São Paulo" de 1800, o Capitão-general Antonio Manoel de Mello Castro e Mendonça já sugeria a criação de uma Academia Fármaco-Cirúrgica para formar os cirurgiões localmente, assim seria necessário trazer de fora apenas os médicos. A idéia era suprir as vilas paulistas com homens habilitados "cientificamente", que seriam pagos pelas câmaras municipais por meio de imposto autorizado por Sua Alteza Real (MENDONÇA, 1961, p. 180). A sugestão de Castro e Mendonça traduzia a falta de indivíduos com formação acadêmica e, ao mesmo tempo, o temor pelo despreparo dos que se aventuravam em exercer tais atividades sem as devidas leituras e práticas, o que começava a incomodar tanto as autoridades, quanto as (poucas) pessoas habilitadas que tentavam demarcar seu espaço de atuação.

Em Campinas, a dificuldade de encontrar médicos e cirurgiões e, posteriormente, a disputa entre diferentes pessoas que exerciam ações de cura, gerou atitudes singulares. Em 1830, um vigário local atestou a competência profissional e honra ilibada, de um vendedor de remédios que havia anos se dedicava também "à arte da medicina pela falta que há de quem cure" (o que, em tese, era proibido). O cidadão atenderia "com toda a exatidão e presteza e com especialidade aos pobres com toda a caridade", sendo recebido pelas mais distintas e ricas famílias do lugar, socorrendo as pessoas da vila, dos sítios e dos engenhos (MARTins, 1996, p. 70). Pessoas “diplomadas" que mora-

${ }^{24}$ A Fisicatura-mor, que regulava os ofícios de cura desde 1808, foi extinta em 1828. Novas formas de regulamentação seriam instituídas, entretanto, no período seguinte ao da extinção daquele órgão, a normatização dos que praticavam diferentes artes de curar ficou sem uma única diretriz definida e seguiu, em parte, o que estava estabelecido desde o início do Oitocentos. Cf.: PIMENTA, 2003a.

${ }^{25}$ C.C., $1829,1^{\text {a }}$ Cia, fogo, 113. C.C., $1829,7^{\text {a }}$ Cia, fogo 122.C.C., $1829,1^{\text {a }}$ Cia, fogo 150. 
vam e atuavam em Campinas, certamente não gostaram, tanto da atuação do concorrente quanto do atestado de sua competência emitido por um leigo: um padre.

Se médicos, cirurgiões e até mesmo boticários, eram poucos, alguns indivíduos, quando não pretendiam recorrer a outros curadores e se suas posses e letras permitiam, buscavam precaver-se pessoalmente dos incertos ataques à saúde. Era aconselhável a posse de alguns medicamentos e de um livro que ensinasse o que fazer quando moléstias ou acidentes ocorriam. ${ }^{26}$ Entre os raros leitores campineiros, ou pelo menos entre os que guardavam livros de medicina e para o preparo de remédios, estavam José Barbosa da Cunha e sua viúva Clara Rita de Sousa. Quanto aos medicamentos, não só letrados ou pessoas da vila adquiriam produtos medicinais: em 1812, a farmácia "do Salles" de Campinas vendeu $22 \$ 000$ réis em remédios para a Fazenda Rio da Prata (município de Jundiaí), pertencente ao Coronel Manoel Elpídio Pereira de Queirós:

Eram recursos de urgência que havia sempre nas fazendas distantes:

1 vidro de 1 onça ${ }^{27}$ de Noz Vomica,

1 de 8 onças de Elixir Paregórico,

2 dos de Arnica (tintura) de 4 onças,

1 de tintura de Macela Galega ou Camomila de 2 onças,

1 de Antimônio de 4 onças,

1 do de Acetato de Amônio ou Espírito de Minderer (era um estimulante [aconselhado] para reumatismo, escarlatina, bexigas, cólicas e até contra embriaguês) (QUEIRÓS, 1965, p. 58).

Assim, marcada pela escassez de letrados, livros e pessoas oficialmente habilitadas nas artes de curar, Campinas adentrou o século XIX, vivenciando, como outras localidades brasileiras, tentativas de inserção social e profissional de diferentes curadores, o que muitas vezes gerou tensão e disputas (o "atestado" do pároco local é significativo) e fez o Capitão-general Castro e Mendonça idealizar uma academia Fármaco-Cirúrgica para a província. Pou-

${ }^{26}$ Os dicionários de medicina doméstica ganhariam grande popularidade no Brasil, principalmente a partir de meados do século XIX. Cf.:FERREIRA, 2003. FIGUEIREDO, 2002, p. 139184.

${ }^{27}$ Aproximadamente 28,7 gramas. 
co a pouco, a importância da instrução letrada e na "verdadeira arte de curar" ampliaria seu espaço (PIMENTA, 2003b), enquanto Campinas sofreria mudanças que transformaram a localidade em um dos principais centros políticos e econômicos do Brasil na segunda metade do Oitocentos. ${ }^{28}$

\section{REFERÊNCIAS}

BÉNIAC, F. O medo da lepra. In: LE GOFF, J. (Org.). As doenças têm história. Lisboa: Terramar, [19-], p.127-144.

DELUMEAU, J. História do medo no Ocidente. São Paulo: Companhia das Letras, 1989.

DUBY, G. Ano 1000 ano 2000. Na pista de nossos medos. São Paulo: Unesp, 1998.

FARIA FILHO, L. M.; VAGO, T. M. Entre relógios e tradições: elementos para uma história do processo de escolarização em Minas Gerais. In: VIDAL, D. G. ; HILSDORF, M. L. S. (Orgs.). Brasil 500 anos: tópicos em história da educação. São Paulo: Edusp, 2001. p. 117-136.

FERREIRA, L. O. Medicina impopular. Ciência médica e medicina popular nas páginas dos periódicos científicos (1830-1840). In: CHALHOUB, S. et al. (Orgs.). Artes e oficios de curar no Brasil. Campinas: Unicamp, 2003. p. 101-122.

FIGUEIREDO, B. G. A arte de curar. Cirurgiões, médicos, boticários e curandeiros no século XIX em Minas Gerais. Rio de Janeiro: Vício de Leitura, 2002.

MACHADO, A. Vida e morte do bandeirante. Belo Horizonte: Itatiaia; São Paulo: Edusp, 1980.

MACHADO, R. et al. Danação da norma. Rio de Janeiro: Graal, 1978.

${ }^{28}$ A partir do final da década de 1880, a prosperidade de Campinas seria, entretanto, abalada pelas epidemias de febre amarela (a varíola já havia castigado o lugar entre 1873 e 1875). Em 1889, a cidade foi devastada: o número de habitantes foi reduzido a cerca de $10 \%$ de seu total (3.500), nos piores dias da doença, devido aos óbitos e à fuga das pessoas. Outros surtos viriam nos anos seguintes e a situação só começou a mudar depois das ações do médico Emílio Ribas, iniciadas em 1896. Ribas conhecia a tese do cubano Carlos Finley sobre a transmissão da febre amarela pelo mosquito stegomyia fasciata (hoje chamado aedes aegypti) (SANTOS FILHO; NOVAES, 1996). Tese que, em poucos anos, ganhou numerosos adeptos e motivou muitas discussões, publicações e ações médico-sanitárias. 
MARIANO, J. Badulaques. São Paulo: Conselho Estadual de Artes e Ciências Humanas, 1979.

MARQUES, V. R. B. Instruir para fazer a ciência e a medicina chegar ao povo no Setecentos. Revista Portuguesa de Pedagogia, Coimbra, Faculdade de Psicologia e de Ciências da Educação, Universidade de Coimbra, ano 37, n. 2, p. 171-183, 2003.

MARTINS, V. Livres, escravos e doenças. Campinas, século XIX. In: ENCONTRO REGIONAL DE HISTÓRIA, ANPUH, 17., 2004, São Paulo. Anais... Campinas, 2004. (CD-ROM)

MARTINS, V. Nem senhores, nem escravos. Campinas: CMU/Unicamp, 1996.

MENDONÇA, A. M. de M. C. e. Memória econômico política da Capitania de São Paulo. Anais do Museu Paulista, tomo XV, São Paulo, 1961.

PIMENTA, T. S. Entre sangradores e doutores: práticas e formação médica na primeira metade do século XIX. Cadernos Cedes, Campinas, v. 23, n. 59, p. 91-102, 2003a.

PIMENTA, T. S. Terapeutas populares e instituições médicas na primeira metade do século XIX. In: CHALHOUB, S. et al. (Orgs.). Artes e oficios de curar no Brasil. Campinas: Unicamp, 2003b. p. 307-330.

QUEIRÓS, C. P. de. Um fazendeiro paulista no século XIX. São Paulo: Imprensa Oficial do Estado, 1965.

QUEIRÓZ, S. R. R. de. Algumas notas sobre a lavoura do açúcar em São Paulo no período colonial. Anais do Museu Paulista, tomo XXI, São Paulo, 1967.

RIBEIRO, A. I. M. A educação da mulher no Brasil colônia. São Paulo: Arte \& Ciência, 1997.

RIBEIRO, A. I. M. A educação feminina durante o século XIX: o Colégio Florence de Campinas, 1863-1889. Campinas: CMU/Unicamp, 1996.

SAINT HILAIRE, A. de. Viajem à Província de São Paulo. Belo Horizonte: Itatiaia/ Edusp, 1976.

SANTOS FILHO, L. de C.; NOVAES, J. N. A febre amarela em Campinas, 18891900. Campinas: CMU/Unicamp, 1996.

SILVA, M. B. N. da. Cultura no Brasil colônia. Petrópolis: Vozes, 1981.

SILVA, M. B. N. da. Sistema de casamento no Brasil colonial. São Paulo: T.A. Queiroz/ Edusp, 1984.

SOUZA, L. de M. e. Desclassificados do ouro. 2. ed. Rio de Janeiro: Graal, 1986.

SOUZA, L. de M. e. O diabo e a terra de Santa Cruz. São Paulo: Companhia das Letras, 1995. 
TSCHUDI, J .J. von. Viagem às Províncias do Rio de Janeiro e São Paulo. Belo Horizonte: Itatiaia; São Paulo: Edusp, 1980.

VILLALTA, L. C. O que se fala e o que se lê: língua, instrução e leitura. In: NOVAES, F.; SOUZA, L. de M. e. (Dir.). História da vida privada no Brasil, 1: cotidiano e vida privada na América Portuguesa. Laura de Mello e Souza (Org.). São Paulo: Companhia das Letras, 2001. p. 331-385.

\section{Fontes}

Censos de Campinas, 1800-1829.

Documentos Interessantes para a história e costumes de São Paulo, São Paulo, v. 30 e 44 , s.d.

Inventários - Centro de Memória da Unicamp, Tribunal de Justiça de Campinas, 18001850 .

Texto recebido em 30 mar. 2005

Texto aprovado em 05 jun. 2005 